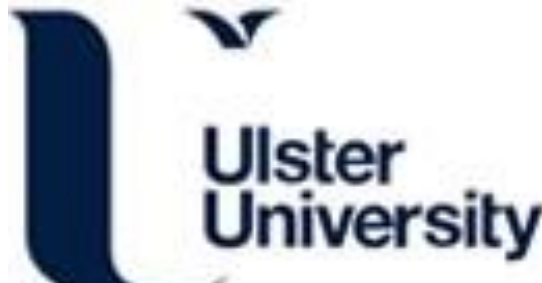

\section{The impact of staff training on special educational needs professionals' attitudes toward and understanding of applied behavior analysis}

Smyth, S., Reading, B. E., \& McDowell, C. (2019). The impact of staff training on special educational needs professionals' attitudes toward and understanding of applied behavior analysis. Journal of Intellectual Disabilities, 23(4), 541-551. https://doi.org/10.1177/1744629517739160

Link to publication record in Ulster University Research Portal

Published in:

Journal of Intellectual Disabilities

Publication Status:

Published (in print/issue): 01/12/2019

DOI:

$10.1177 / 1744629517739160$

\section{Document Version}

Author Accepted version

\section{General rights}

Copyright for the publications made accessible via Ulster University's Research Portal is retained by the author(s) and / or other copyright owners and it is a condition of accessing these publications that users recognise and abide by the legal requirements associated with these rights.

\section{Take down policy}

The Research Portal is Ulster University's institutional repository that provides access to Ulster's research outputs. Every effort has been made to ensure that content in the Research Portal does not infringe any person's rights, or applicable UK laws. If you discover content in the Research Portal that you believe breaches copyright or violates any law, please contact pure-support@ulster.ac.uk. 


\section{The impact of staff training on special educational needs professionals' attitudes toward and understanding of applied behavior analysis}

Sinéad Smyth

Dublin City University, Ireland

\section{Benjamin E Reading}

Ulster University, UK

\section{Claire McDowell}

Ulster University, UK
Journal of Intellectual Disabilities

(C) The Author(s) 2017

Reprints and permission: sagepub.co.uk/journalsPermissions.nav DOI: I0.II77/I7446295|7739|60 journals.sagepub.com/home/jid

Date accepted: 28 September 2017

\begin{abstract}
Background: Research-based evidence points to the efficacy and value of applied behavior analysis (ABA) in meeting the needs of individuals with learning disabilities and autism. Nonetheless, public, government, and professional perception of ABA can be negative. The current study was designed to measure the impact of a short intervention on professionals' attitudes toward, and knowledge of, ABA. Method: Teachers and classroom assistants from two separate schools for children with severe learning difficulties completed a self-report survey on knowledge of and attitudes toward $A B A$. They were then presented with a 90-min training module designed to increase their knowledge of the history of ABA and their functional assessment skills. Following training, the selfreport was readministered. Results: The mean scores for each group increased only after the training had been delivered. Discussion and conclusions: Further research is needed to address the impact of training on classroom practice.
\end{abstract}

\title{
Keywords
}

Applied behavior analysis (ABA), staff training, attitudes, knowledge

\section{Corresponding author:}

Sinéad Smyth, School of Nursing and Human Sciences, Dublin City University, Glasnevin, Dublin 9, Ireland. Email: sinead.smyth@dcu.ie 
There is a wealth of peer-reviewed, scientifically validated evidence regarding the efficacy of applied behavior analysis (ABA) in the treatment of behavior challenges and behavior deficits in children with autism spectrum disorders (ASD) and/or intellectual disabilities (DeMyer, et al., 1981; Hingtgen and Bryson, 1972). Baer, Wolf, and Risley (1968) asserted that a technology of behavior is much more likely to be accepted and valued by society when it can be shown to have useful applications in areas such as crime, mental health, and learning disability. That technology and those applications are now being realized (e.g. Foran, et al., 2015; Gendreau, et al., 2014) more than ever available in abundance; however, the universal acceptance of the discipline that these writers called for has arguably not been realized (Keenan, et al., 2007; Walsh, 1997). ABA has, however, seen surges in popularity and demand, at different times and in different places. In recent years, ABA has become increasingly prominent in special needs education in Northern Ireland. While there is still no dedicated ABA school in the province, there are a number of established organizations and individuals promoting and practicing ABA in a range of contexts. Despite these recent changes, it appears, anecdotally through the experience of the second author as a special needs educator, to still be the case that the majority of special needs educators in Northern Ireland have had very limited training in the use of ABA. Grey, Honan, McClean, and Daly (2005) examined the effectiveness of teacher training in ABA in the Republic of Ireland, but no such studies exist for Northern Ireland. Furthermore, there are no published studies which examine the attitudes to ABA among special needs practitioners.

Keenan, Kerr, and Dillenburger (2000) noted continued widespread misconceptions in Northern Ireland concerning ABA due to a lack of familiarity and training in ABA, "which in turn has lead to superficial understanding and misinformation" (p. 153). Keenan et al. identified four key misconceptions which underlie and intensify the opposition toward ABA in some professional circles. The present study is not the vehicle to unpack and discuss these erroneous assumptions, but it is possible that lack of knowledge or erroneous assumptions about an approach or methodology may be linked to negative attitudes. Indeed, survey of teachers in Saudi Arabia indicated that teachers who have received ABA or behavior management training tended to have higher levels of knowledge and frequency of use of ABA strategies compared to teachers with no such training (Alotaibi, 2016). A survey in the United States by McCormick (2012) also reported a positive relationship between the use of ABA and attitudes toward the use of ABA and knowledge of ABA.

In 1999, the US Surgeon General stated that "Thirty years of research demonstrated the efficacy of applied behavioral methods in reducing inappropriate behavior and in increasing communication, learning, and appropriate social behavior." (Satcher, 1999). That endorsement of the use of ABA in one country notwithstanding, many believe it would be an error to focus solely on one approach and ignore others. Rather, professionals working in the area of special education should have a large repertoire of skills and individualize programs by using a method that is most appropriate for a certain individual or behavior. Although behavior analysts would argue that ABA does just that (Leaf et al., 2016), it should be recognized that a more eclectic approach than ABA does not, or should not, exclude it. With that in mind, the current study focused on a brief training module to add to the special needs educators' existing knowledge and skills in ABA rather than an extensive training in ABA. In this regard, the current study differed considerably from other research which focused on in-depth ABA training (e.g. Fallon et al., 2011; Grey et al., 2005). It also adds to the literature through the use of a second, delayed intervention group, which in many ways acted to control for practice effects (see Allen and Bowles, 2014 for a brief intervention which did not employ a control). 
Table I. Profile summary for the intervention and delayed intervention groups.

\begin{tabular}{|c|c|c|}
\hline & Intervention group & Delayed intervention group \\
\hline Number of participants & 16 & 20 \\
\hline Gender & Mixed & All female \\
\hline $\begin{array}{l}\text { Age range of children in } \\
\text { school }\end{array}$ & $3-19$ & $3-8$ \\
\hline Pupil profile & $\begin{array}{l}\text { Autism spectrum disorder; wide range of disabilities } \\
\text { from moderate to profound; often with multiple } \\
\text { diagnoses }\end{array}$ & $\begin{array}{l}\text { Autism spectrum disorder; } \\
\text { specific learning disability }\end{array}$ \\
\hline School location & Urban & Urban \\
\hline
\end{tabular}

Given the perception that ABA is misunderstood and misrepresented in special education (Keenan et al., 2000), the purpose of the current study was to determine the impact of brief history and skills training on the attitudes and knowledge levels of special education professionals. Grey et al.'s research (2005) into the effectiveness of teacher training in ABA was spread out over 7 months and involved some $90 \mathrm{~h}$ of classroom instruction. Support plans produced by the newly trained teachers were implemented and, on average, the behaviors targeted showed an $80 \%$ change in frequency. The current study was considerably more condensed and aimed to assess, if a single after-school training session was followed by changes in self-reported attitudes to and knowledge of ABA. Aside from the geographical and jurisdictional context, other differences to Grey et al.'s study are the inclusion of a control group, a focus on outcome measures of attitudes and knowledge rather than practice and the inclusion of classroom assistants as well as teachers.

In the absence of widespread formal staff training in ABA, the focus of the present study was on investigating the knowledge of and attitude toward ABA by education practitioners. Specifically, would levels of knowledge and positive attitudes increase the following exposure to a brief training module designed to teach the history of ABA as well as functional assessment.

\section{Method}

\section{Participants}

Participants were staff members recruited from schools for children with severe learning difficulties in Northern Ireland and had at least 12 months experience in post. The schools were randomly assigned to either an intervention or delayed intervention group and participants' group membership was therefore determined by the school at which school they worked. All participants were either teachers or classroom assistants and none had received formal training in ABA; however, they may have used techniques frequently used by behavior analysts without knowing why. A summary of the group profiles can be seen in Table 1 . Of the 50 participants originally recruited, 36 completed all sessions for their group over the duration of the study, 16 from the intervention group and 20 from the delayed intervention group. The sample being one of convenience, the intervention group was a mixed-gender group, whereas the delayed intervention group was comprised of females only. In accordance with the ethical guidelines of the Ulster University Research Ethics Committee, participants were informed of the nature of the study during a briefing session and informed consent was gained at a later date. 
Journal of Intellectual Disabilities $X X(X)$

\section{Apparatus and materials}

The study was conducted in the schools in which the groups worked. It was conducted after work hours and during training afternoons. Paper-based resources for the study included an information sheet, consent form, and the self-report survey which was employed as the measurement tool. The self-report measure was designed by the second author and reviewed and revised by the other authors and an independent person. This measure was designed based on the content of the training module and with reference to other assessments of training. It is not intended to be a scale and the purpose of the current study was not to validate it but to compare responses to the measure before and after training on ABA had been received. The measure contained 32 statements, 16 of which were related to knowledge and 16 to attitudes. Participants were asked to rate their responses to each statement on a 1-5 Likert-type scale (where $1=$ Completely disagree and $5=$ Completely agree), allowing for a maximum possible score of 80 each for knowledge and attitudes. The attitudes and knowledge statements were mixed in a random sequence and 10 statements were negatively phrased, containing either negative or factually inaccurate statements about ABA. Further information is available in the "Dependent measures" section and a copy of the measure can be obtained through contacting the first author. Participants were urged to be honest and to give their first response and were assured that all answers would be treated with the utmost confidentiality.

The intervention was a training module which was presented on Microsoft Powerpoint via a laptop computer and projector. The training module included some historical information about the origins of behavior analysis more generally and ABA more specifically. Operant behavior and conditioning were covered as was functional assessment and paired stimulus preference assessment. It also included two workshop elements in which staff worked in small groups to complete practical activities. In the first activity, participants were provided with a basic A-B-C chart to complete. In the second activity, participants worked in groups of three to complete a paired stimulus preference assessment. In order to complete the assessment, each small group was provided with four toys at random which they used for the duration of the activity. The assorted toys included bubbles, teddy bears, 'Silly Putty', rubber spiders, spinning tops, and various balls and the purpose of the exercise was to identify, systematically, the preferred toy. The two workshop elements were chosen because of their practical utility in the classroom from day to day. The purpose of this combination of training elements overall was to increase positive attitudes toward and knowledge of ABA. A copy of the presentation employed may be obtained by contacting the first author.

\section{Experimental design}

A mixed within-between participants design was used to examine the effects of the training module on the staff members' knowledge of and attitudes toward ABA. Both groups completed a survey three times (within-groups variable); however, the time at which the staff training intervention was received varied by group (between-participants variable). The intervention group received the intervention between survey implementation time 1 and time 2 and the delayed intervention group received the intervention between time 2 and time 3 . Times 1, 2, and 3 were all on separate days with the exact spacing outlined in the "Method" section. The intervention group therefore completed two follow-up sessions; the delayed intervention group completed one. This was to ensure balance across the groups and control, as much as possible, for practice effects. 


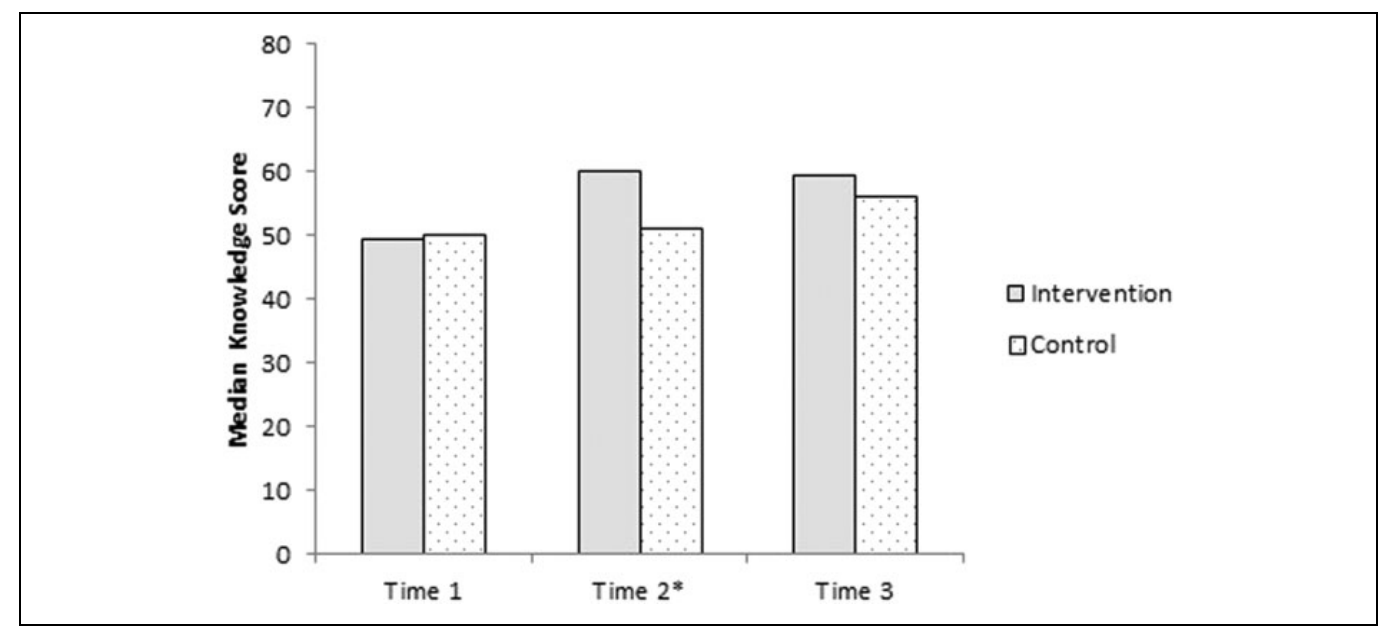

Figure I. A schematic outline of the timeline for both the intervention and delayed intervention group.

\section{Dependent measures}

At all three response times, data were collected using a paper-and-pencil survey which participants completed separately but in a group setting. The dependent variables were attitudes toward ABA and knowledge of ABA. These were measured using a 32-item survey in which participants were required to respond by rating their agreement to each item on a five-point Likert-type scale.

Attitudes toward ABA were measured in 16 of the 32 items. Sample items included: "Introducing any type ABA technique would be impractical and unrealistic in this school.", "Applied Behavior Analysis should be a part of the day-to-day classroom operation.", and "Functional Assessment is or could be an increasingly regular feature of my professional practice."

Knowledge of $A B A$ was similarly measured using 16 items. Sample items include: "I could explain some of the basics of Behavior Analysis to other professionals", "ABA has been specifically designed as 'a therapy for Autism", and "Data collection is a key element to understanding the function of a behavior."

\section{Procedure}

Each group took part in four sessions. The content of sessions is outlined in Figure 1. The first three sessions were spaced 6 or 7 days apart; the final session interval was delivered 2 days after the third. For each group, three of the four sessions involved administration of the self-report, the remaining session was the training module. In session 1, the intervention group was briefed on the information sheet, received participant numbers, and signed consent forms. They then completed their baseline self-report to complete the first session. Session 2 was the training module for the intervention group.

At the beginning of the training, participants were seated in their staff room and told the estimated finish time. They also were told the basic structure of the training. The first third of the session was presented as a talk by the researcher and was entitled "About ABA." This very briefly covered the timeline of development of psychology and how B.F. Skinner and others contributed to the formation of ABA. The scientific heritage and nature of the discipline was then discussed, with 
reference to peer-reviewed journals, the strict governance of research and practice, and the "natural science" approach to analyzing and applying principles of behavior. Some of the misconceptions surrounding $\mathrm{ABA}$ were countered, including an explanation that ABA is not a therapy for autism. This was done by detailing a sample range of studies unconnected with education, special needs, or ASD and by contrasting a packaged or therapeutic approach with the broad discipline of ABA. Finally, ABA was defined as a scientifically validated framework of principles within which behavior can be analyzed and changed.

The first practical workshop of the session was preceded by an explanation of the three-term contingency of operant conditioning and the importance of understanding the function of a behavior. Some examples were given of both challenging behaviors and everyday "typical" behaviors, broken down into their component antecedents, behaviors, and consequences. Participants were divided into groups of three (or four), provided with a basic $\mathrm{ABC}$ chart and asked to provide their own example, which they then shared with the wider group.

The second practical involved participants remaining in their groups and completing a paired stimulus assessment. Once the terms were explained and the rationale behind establishing the relative strength of reinforcers discussed, sets of four toys were distributed along with an assessment sheet. Each group of three assigned one member to be the "pupil," one to be the "teacher," and one to be the observer responsible for data collection. They then completed the sheet in accordance with the researcher's instructions and recorded which of the four toys emerged through the assessment process as the "preferred" item.

After sharing the outcomes of each small group's assessment, the training was drawn to a conclusion. The content of the presentation was reviewed, and participants were thanked for their cooperation and assistance. Subsequent to the training module, the intervention group completed two further sessions. Session 3 consisted of a readministration of the self-report, as did session 4 .

The content of the sessions was exactly the same for the delayed intervention group but the order was different. This was implemented to ensure that any increase noted in the self-report scores after the intervention was not simply due to familiarity with the measurement tool or chance. While session 2 for the intervention group consisted of the training module, the delayed intervention group remained in baseline and completed a second self-report. The delayed intervention group then received the training module in session 3 and completed one additional selfreport in session 4 . The fourth session for the delayed intervention group cannot be considered a maintenance probe given that it was so close to the training in session 3 but was instead a measure of the impact of the training.

\section{Data analysis}

Data were entered into SPSS. Negatively worded items were reversed and responses for each participant were summed to give the overall attitude and knowledge scores. There was a maximum individual score of 80 for each variable, with higher scores indicating higher levels of knowledge or more positive attitudes. Given the small sample size, nonparametric tests were conducted between and within groups.

\section{Ethical approval}

All procedures performed in this study were in accordance with the ethical standards of the Ulster University Research Ethics Committee and with the 1964 Helsinki declaration and its later amendments. 


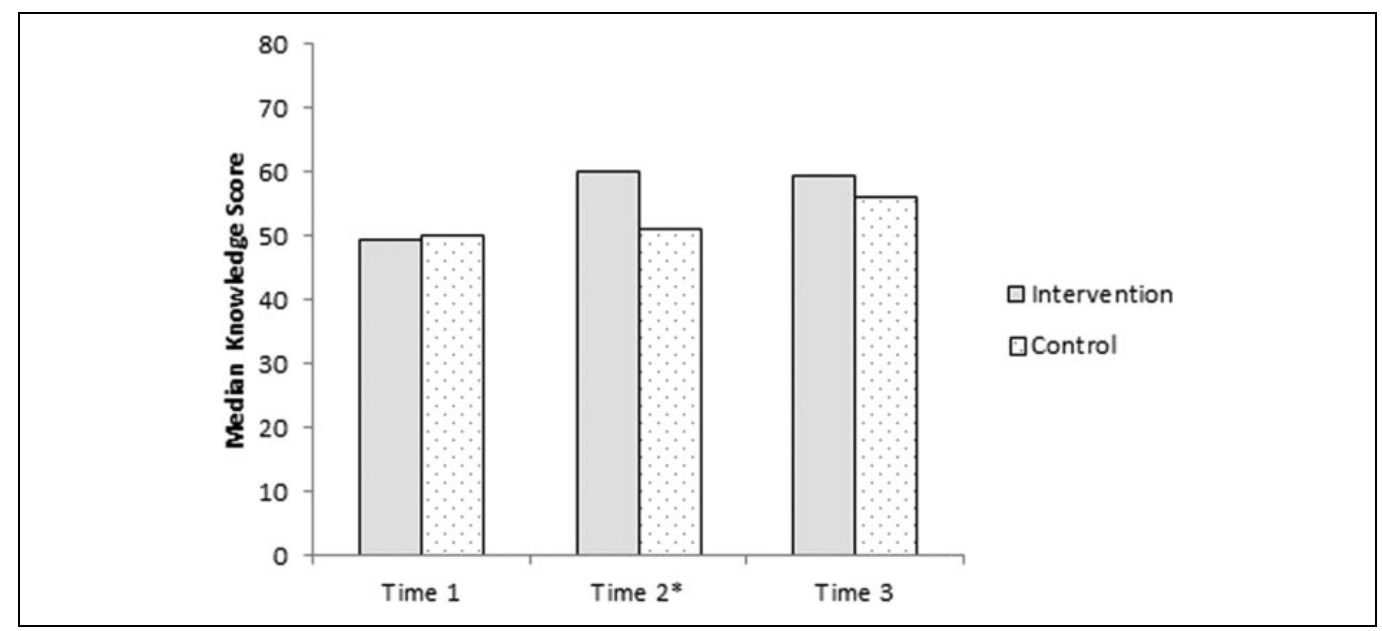

Figure 2. Median knowledge scores per group per session. *Significant differences between the groups. Significant within-groups differences were seen between times I and 3.

\section{Results}

\section{Knowledge}

Knowledge levels at times 1-3 may be seen in Figure 2.

Between-groups analysis. Three Mann-Whitney tests were conducted in order to compare the knowledge scores of the two groups at each of the time points. In order to reduce the risk of a type 1 error, a Bonferroni correction was conducted and the $\alpha$ level was set at 0.017 . The first test compared responses given by the two groups at time 1 . No significant differences were found between the knowledge scores of the intervention group $(\mathrm{Mdn}=49.5)$ and the delayed intervention group ( $\mathrm{Mdn}=50)$ pre-intervention, $U=159, p=.99$. This is particularly important given that the nature of the study meant participants had to be trained in their school groups and could not be randomly assigned to the intervention and delayed intervention groups. At time 2, following training for the intervention group, a significantly higher mean knowledge score $(\mathrm{Mdn}=60)$ was demonstrated relative to the delayed intervention group $(\mathrm{Mdn}=51)$ which had not yet received training, $U=69.5, p=0.003$. Once the delayed intervention group received training, no significant difference was found between it $(\mathrm{Mdn}=56)$ and the intervention group $(\mathrm{Mdn}=59.5)$ at time $3, U=121.5, p=0.22$.

Within-groups analysis. Wilcoxon signed-rank tests were conducted in order to compare time 1 and time 3 knowledge scores for each group. The median knowledge score at time 3 was significantly higher than at time 1 for both the intervention group, $z=-2.93, p=0.003$, and the delayed intervention group, $z=-2.63, p=0.008$ (adjusted $\alpha 0.0025$ ).

\section{Attitudes}

Attitudes at times 1-3 may be seen in Figure 3. 


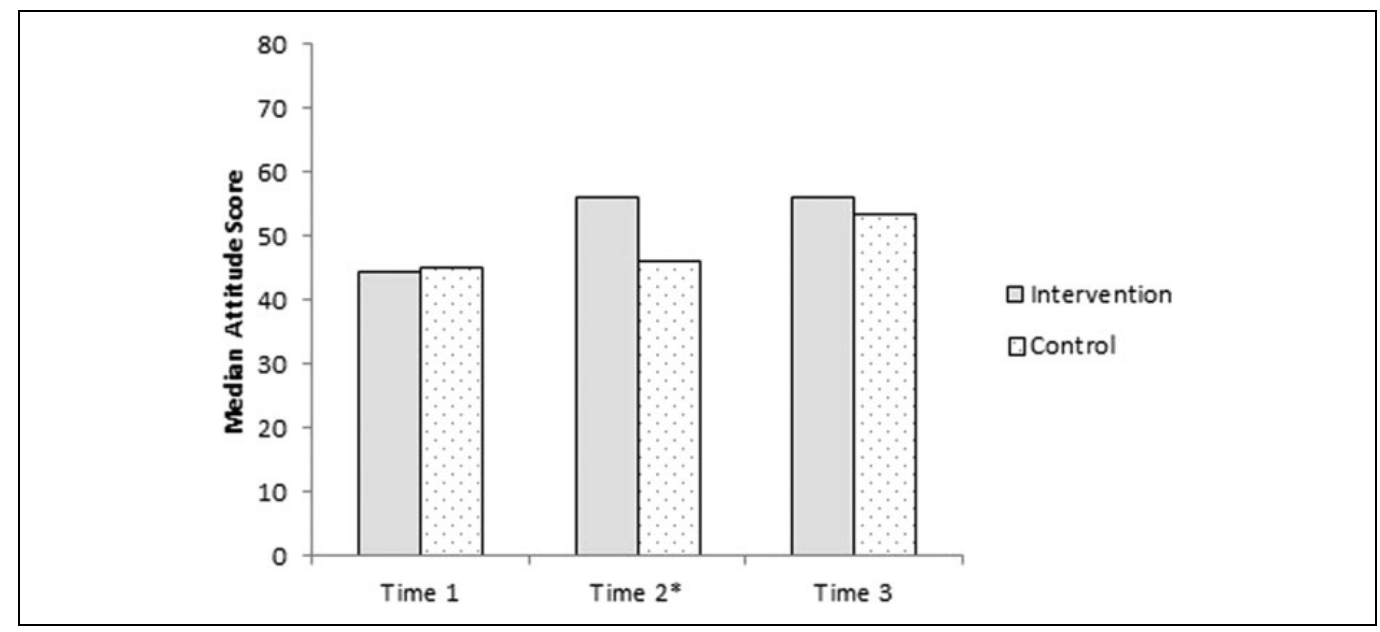

Figure 3. Median attitude scores per group per session. *Significant differences between the groups. Significant within-groups differences were seen between times I and 3.

Between-groups analysis. A further three Mann-Whitney tests were conducted in order to compare the attitude scores of the two groups at times 1,2, and 3. Bonferroni corrections were conducted as before and the $\alpha$ level was set at 0.017 . As for knowledge, no difference in attitude levels between the groups was noted at time 1. Furthermore, the only significant difference between the groups was found at time 2, when the intervention group reported significantly more positive attitudes $(\mathrm{Mdn}=56)$ than the delayed intervention group $(\mathrm{Mdn}=46)$.

Within-groups analysis. As for the knowledge scores, Wilcoxon signed-rank tests were conducted in order to compare time 1 and time 3 attitude scores for each group. The median knowledge score at time 3 was significantly higher for the intervention group, $z=-3.416, p=0.001$, and for the delayed intervention group, $z=-3.543, p=0.000$ (adjusted $\alpha 0.0025$ ).

\section{Discussion}

The purpose of the current study was to investigate the impact of training on attitudes to and knowledge of ABA among special needs professionals. It was found that the mean scores on both measures differed significantly between groups soley at time 2 when only the intervention group had received the intervention, and indeed this group scored significantly higher than the delayed intervention group on the self-report measures. Before the intervention had been administered, and after both groups had experienced it, there were no significant differences. This was corroborated by within-groups analyses which demonstrated that for the intervention group, there was a significant increase in the mean score following intervention, which was maintained in a follow-up. For the delayed intervention group, there was no significant difference in the mean scores for both baseline condition sessions. This group did, however, also produce significantly increased scores in both attitudes and knowledge after the training. These data would seem to indicate, therefore, that a single afternoon training session for teachers and classroom assistants leads to increased knowledge of, and more positive self-reported attitudes toward, ABA. 
As previously discussed, ABA has generated a wealth of peer-reviewed research to substantiate the claims of its proponents (DeMyer, et al.,1981; Hingtgen and Bryson, 1972; Keenan and Gallagher, 2007). However, research indicates ABA is not a widely accepted, promoted, or accessed form of support for young people with learning difficulties and/or autism (Walsh, 1997). The present study was not concerned with training behavior analysts, but rather with raising awareness, improving knowledge, and challenging attitudes. The outcome of the current study was that a 90-min after-school training module produced significant changes in knowledge and attitudes regarding $\mathrm{ABA}$. This research has shown that in this small sample, simple and short training modules can have a positive impact on knowledge of, and attitudes to, ABA. It should be noted that both groups demonstrated moderate preexisting knowledge levels and positive attitudes. Furthermore, although the increases in knowledge and attitudes were statistically significant, the differences were small and the practical implications of these increases are not known. It would be of interest to conduct a follow-on study in the future to determine whether this short intervention had a lasting effect.

The findings have implications for special needs training for educators in areas where ABA techniques and principles are not the main approach. It could also be argued that brief training for staff in ABA-led facilities may be important, particularly for staff members who do not have formal qualifications in ABA. It should also be recognized that other professional groups commonly in contact with those with special education needs and their educators may also benefit from brief training. These groups may include social workers, medical staff, and politicians. The implications of the current findings for these groups need to be explored in future studies.

While the current data are interesting and point toward the need for training, generalizing from the current data is hampered by a number of issues. Firstly, the sample from one school, in particular, was considerably smaller than anticipated (16) due in part to attrition throughout the course of the study. There are numerous factors which may or may not have contributed to participants not completing all four sessions, and it is impossible to speculate about these with any confidence. Secondly, the dates available for training were dependent on the needs of the schools and training commitments already in existence. The final intersession interval for both groups was only 2 days. Ideally, this would have been longer to allow more confidence in the results. Furthermore, and if time had allowed, a longer term probe of response maintenance (weeks or months later) would likely have been informative as to the maintenance of increased knowledge and more positive attitudes. Thirdly, a more detailed profiling of participants would have provided scope for more indepth data analysis. Between-groups investigations could then have looked at the answers of classroom assistants versus those of teachers or the responses of relatively newly qualified staff compared to those with 5 or 10 years' experience. In this instance, such information was not specifically asked for, nor was there any indication of what previous training in ABA any of the participants had individually or collectively received.

Nevertheless, the current study adds to the literature in a number of valuable ways. Grey et al. (2005) pointed out the lack of control group in their own study meant that the influence of some potential extraneous variables (e.g. familiarity and chance) could not be ruled out. This issue was also apparent in other published studies which employed both long (Fallon et al., 2011) and short (Allen and Bowles, 2014) interventions. The current study addressed this shortcoming through the use of a delayed intervention group who received the intervention at a later stage than the intervention group. Secondly, the narrow focus of the current study affords some confidence in the result. As an area in which there are no previous published studies, it is important that this research focused on the simple investigation of the impact of training. 
The impact of training on classroom practice was not addressed in this study, nor did the length of the study allow for or lead to opportunities for significant practical training. Future research could address this issue as well as comparing participants based on years' experience, previous training, classroom role, or training establishment attended. Intention to practice may also be a useful means for future research to unpack variables other than attitudes which may affect practice. Such efforts would afford a greater insight into some of the other factors that influence attitudes to and knowledge of ABA.

\section{Authors' note}

Further details on research materials can be obtained from the corresponding author.

\section{Declaration of Conflicting Interests}

The author(s) declared no potential conflicts of interest with respect to the research, authorship, and/or publication of this article.

\section{Funding}

The author(s) received no financial support for the research, authorship, and/or publication of this article.

\section{References}

Allen KA and Bowles TV (2014) Examining the effects of brief training on the attitudes and future use of behavioral methods by teachers. Behavioral Interventions 29(1): 62-76. DOI:10.1002/bin.1376.

Alotaibi AA (2016) Knowledge and use of applied behavior analysis among teachers of students with autism spectrum disorder in Saudi Arabia. Unpublished Dissertation. Washington State University, USA.

Baer DM, Wolf MM and Risley TR (1968) Some current dimensions of applied behavior analysis1. Journal of Applied Behavior Analysis 1(1): 91-97. DOI: 10.1901/jaba.1968.1-91.

DeMyer MK, Hingtgen J and Jackson R (1981) Infantile autism reviewed: a decade of research. Schizophrenia Bulletin 7: 388-451. DOI: 10.1093/schbul/7.3.388.

Fallon M, Zhang J and Kim EJ (2011) Using course assessments to train teachers in functional behavior assessment and behavioral intervention plan techniques. The Journal of International Association of Special Education 12: 50-58.

Foran D, Hoerger M, Philpott H, et al. (2015) Using applied behaviour analysis as standard practice in a UK special needs school. British Journal of Special Education 42(1): 34-52.

Gendreau P, Listwan SJ, Kuhns JB, et al. (2014) Making prisoners accountable: are contingency management programs the answer? Criminal Justice and Behavior 41(9): 1079-1102.

Grey IM, Honan R, McClean B, et al. (2005) Evaluating the effectiveness of teacher training in applied behaviour analysis. Journal of Intellectual Disabilities 9(3): 209-227. DOI: 10.1177/17444629505056695.

Hingtgen JN and Bryson CQ (1972) Recent developments in the study of early childhood psychoses: infantile autism, childhood schizophrenia, and related disorders. Schizophrenia Bulletin 5: 8-54. DOI: 10.1093/ schbul/1.5.8.

Keenan M, Dillenburger K, Doherty A, et al. (2007) Meeting the Needs of Families Living with Children Diagnosed with Autism Spectrum Disorder. (Final Report. p.184). University of Ulster, Coleraine, NI.

Keenan M, Kerr KP and Dillenburger K (2000) Conclusion and way ahead. In: Keenan M, Kerr K and Dillenburger K (eds) Parents' Education as Autism Therapists: Applied Behaviour Analysis in Context. London, UK: Jessica Kingsley Publishers, pp. 152-159.

Leaf JB, Leaf R, McEachin J, et al. (2016) Applied behavior analysis is a science and, therefore, progressive. Journal of Autism and Developmental Disorders 46(2): 720-731. 
McCormick JA (2012) Inclusive elementary classroom teacher knowledge of and attitudes toward applied behavior analysis and autism spectrum disorder and their use of applied behavior analysis. Dissertation Abstracts International Section A 72: 2367.

Satcher D (1999) Mental health: a report of the surgeon general rockville, MD: US department of health and human services, substance abuse and mental health services administration, center for mental health services, national institutes of health, national institute of mental health. Available at: https://profi les.nlm.nih.gov/ps/access/NNBBHS.pdf (accessed 14 February 2017).

Walsh P (1997) Bye-bye behaviour modification. In: Dillenburger K, O’Reilly M and Keenan M (eds) Advances in Behaviour Analysis. Dublin: University of Dublin Press, pp. 91-102. 